\title{
高强 PC 钢棒预应力混凝土板静载试验分析研究
}

\section{Study on Static Load Test of Prestressed Concrete Slab with High Strength Pcsteel Bar \\ 徐志彪}

Zhibiao Xu

杨凌职业技术学院 建筑工程分院

中国·陕西 杨凌 712100

Yangling Vocational and Technical College

Construction Engineering Branch,

Yangling, Shaanxi, 712100, China

基金项目：杨凌职业技术学院 2018 年度 自然科学研究基金项目《高强 $30 \mathrm{MnSi}$ 钢 棒预应力混凝土结构的分析与研究》

(A2018026)
【摘要】论文通过配置高强 PC 钢棒的预应力混凝土单向板的正截面承载力静载试验, 为 分析预应力筋的混凝土板正截面承载力力学参数提供试验数据; 以预应力混凝土板的试 验数据为基础, 研究 PC 钢棒预应力混凝土板正截面承载力的主要影响因素。

【Abstract】This paper provides experimental data for analyzing the mechanical parameters of normal section bearing capacity of prestressed concrete one-way slabs with high-strength PC steel bars through static load tests of normal section bearing capacity. Based on the experimental data of prestressed concrete slabs, the main influencing factors of the normal section bearing capacity of PC steel bar prestressed concrete slabs are studied.

【关键词】预应力混凝土; 静载; 承载力

【Keywords】prestressed concrete; static load; bearing capacity

【DOI】10.36012/etr.v2i3.1429

\section{1 预应力混凝土板试验材料}

本试验配制经热处理后抗拉强度达 $1615 \mathrm{MPa}$ 的 PC 钢棒 作为预应力筋, 进行预应力单向板简支试验, 先张法施工工艺。

试验板为单向板形式, 截面尺寸为 $b \times h=500 \mathrm{~mm} \times 100 \mathrm{~mm}$, 板全长 $4200 \mathrm{~mm}$, 净跨 $3800 \mathrm{~mm}$ 。钢棒呈条状直线布设, 钢棒重 心至板底距离为 $25 \mathrm{~mm}^{[1]}$ 。在试验过程中, 忽略其他影响因素, 只分析钢棒有效预应力及配筋率对承载力的影响，张拉控制 系数为 0.5 、板相对受压区高度 0.15 。试验板选用混凝土为实 际施工中采用的 C50 混凝土。试验板参数如表 1 所示。试验 板均采用三分点加载, 具体加载程序按以下步骤进行。

(1)先采用 0.02 进行预加载,再逐渐卸载。保持 3 次反复 操作, 确保试验仪器正常及支座不再发生变形。

(2)在试验板发生开裂前, 按 0.05 倍极限荷载进行分级加 载, 保证试验数据的准确性。

(3)直到试验板发生开裂后, 继续逐渐增加荷载级至 0.1 。分 级加载过程中, 若发生卸荷, 务必在后续加载过程中进行补充。

(4)当加载至极限荷载时, 试验板刚度会逐渐降低, 采用分 级加载进行控制时, 试验板在各级荷载下位移过大, 从而导致 试验数据不准确。因此当加载至 0.8 , 采用变形量来进行加载控 制, 以试验板三分点处位移变形接近 $20 \mathrm{~mm}$ 来控制各级加载。

(5)一直加载至试验板发生破坏阶段时, 观察试验板破坏 情况, 并进行缓慢卸载。
表 1 试验力学参数

\begin{tabular}{c|c|c|c|c|c|c}
\hline $\begin{array}{c}\text { 抗拉强度 } \\
f_{p l k} / \mathrm{MPa} \text { 张拉控 }\end{array}$ & $\begin{array}{c}\text { 实际受压 } \\
\text { 制系数 }\end{array}$ & $\begin{array}{c}\text { 区相对受压度 } / \mathrm{mm} \\
\text { 区高度 }\end{array}$ & 根数 & $\begin{array}{c}\text { 面积 } \\
/ \mathrm{mm}^{2}\end{array}$ & $\begin{array}{c}\text { 极限弯矩 } M_{u} \\
/(\mathrm{kN} \cdot \mathrm{m})\end{array}$ \\
\hline 980 & 0.5 & 10.52 & 0.17 & 4 & 201 & 13.86 \\
\hline
\end{tabular}

\section{2 试验过程}

依据结构试验规范, 试验板留设 6 个立方体试块, 并在试 验时间测定试块强度, 确定试验板混凝土抗压强度。并以此对 混凝土的棱柱体抗压强度、弹性模量、抗拉轻度进行推算 ${ }^{\left[{ }^{[2]}\right.}$ 具体推算公式按 GB/T 50152-2012《混凝土结构试验方法标 准》规定:

$$
\begin{gathered}
f_{c, m}=0.76 \times f_{c u, m} \\
E_{c, m}=\frac{10^{5}}{2.2+\frac{34.7}{f_{c u, m}}} \\
f_{t, m}=0.395 \times f_{c u, m}^{0.55}
\end{gathered}
$$

式中, $f_{c u, m}$ 为混凝土立方体试块抗压强度; $f_{c, m}$ 为混凝土棱柱 体抗压强度; $f_{t, m}$ 为混凝土棱柱体抗拉强度; $E_{c, m}$ 为混凝土抗压 弹性模量。

混凝土板所对应的混凝土立方体试块的材性测试及计算 结果如表 2 所示。

\section{表 2 预留立方体混凝土试块材性试验结果}

\begin{tabular}{c|c|c|c}
\hline$f_{c u, m} / \mathrm{MPa}$ & $f_{c, m} / \mathrm{MPa}$ & $f_{t, m} / \mathrm{MPa}$ & $E_{c, m} / \mathrm{MPa}$ \\
\hline 55.96 & 42.36 & 3.59 & 35699.88 \\
\hline
\end{tabular}




\section{实验与研究 Experiments and Research}

当加载至 $4 \mathrm{kN}$ 时, 试验板正面出现第一条坚直裂缝; 当 加载至 $10 \mathrm{kN}$ 时, 荷载位移曲线出现明显拐点; 加载至 $24.2 \mathrm{kN}$ 时, 试验板受压区出现起皮现象, 以此判断试验板已经破坏。 随后进入卸载阶段, 依据试验板位移变形量进行加载控制, 试 验板位移不断增加, 荷载逐渐降低。当荷载降低至 $20 \mathrm{kN}$ 时, PC 钢棒出现明显颈缩破坏, 试验板的变形突然增加, 钢棒被 拉断。试验板加载的荷载一位移曲线如图 1 所示。

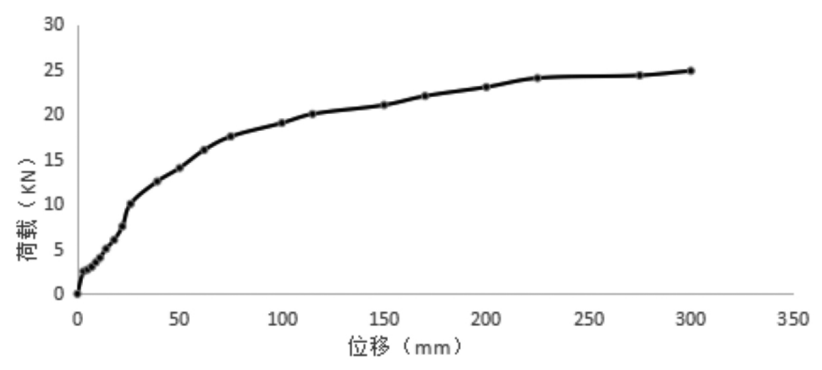

图 1 试验板荷载一位移曲线图

\section{3 试验结果}

试验板实测开裂弯矩为 $7.2 \mathrm{kN} \cdot \mathrm{m}$, 实测极限荷载为 $24.2 \mathrm{kN}$, 通过对试验过程中试验板的变形及破坏规律, 做出以 下几点分析。

\section{（上接第 162 页）}

(8)床旁查房。系统支持对接查房系统，交互终端集成 RFID 模块, 医生可通过在床旁交互终端上刷卡即时调取患者 信息、检查检验报告、影像资料,供医生查阅、分析, 为医生诊 断提供即时、准确依据, 有利于医生对病人的诊断与治疗。

9信息发布。系统支持通过信息发布服务器向床旁交互 终端发布推送文字、图片、音视频等内容。

(10)营养点餐。系统支持对接医院餐饮系统, 患者可通过床 旁交互终端实现营养点餐。

(11)服务评价。患者通过床旁交互终端可对医生、护士、就 医环境等综合服务进行评价。

\section{ICU 探视技术}

\section{1 系统设计及组成}

传输方式采用全数字,基于 TCP/IP 以太网, 主要由床位 分机、家属探视分机、护士站管理主机、服务器、IP 网络通信 线路组成。探视终端采用音视频一体化设备; 内置高清摄像 头, 视频清晰度达到 1080P; 通话采用全双工对讲模式, 探视双 方音视频清晰、流程; 床位分机还可以显示患者相关的信息。

\section{2 系统功能}

(1)可视通话。护士站管理主机、家属分机、病床分机间均
(1)试验板受压区混凝土受压至极限压应变而被压碎作为 板的极限承载力。卸载过程中, 位移控制加载, 直至钢棒被拉 断丧失承载力, 试验结束。

(2)本试验以测定板的正截面极限承载力为目标, 判断依 据为混凝土达到极限压应变或钢棒被拉断。

(3)由试验板的荷载一跨中位移曲线可以看出, 加载过程 中, 出现 3 个明显的拐点将曲线分为 4 段, 此拐点可看作是对 应于试验板的开裂荷载、钢棒的屈服荷载、极限荷载, 图中拐 点即视为对应强度。开始加载时, 试验板发生弹性变形, 位 移一荷载呈线性变化。当试验板发生开裂后, 受拉区混凝土退 出工作, 试验板刚度发生明显降低, 变形迅速增大, 曲线开始 出现第一个拐点。继续加载至钢棒到达屈服强度时, 钢棒开始 产生塑性变形, 继续加载, 荷载增加较少, 变形量却很明显, 出 现第三个拐点, 达到极限压应变, 对应荷载为极限荷载。试验 板钢棒被拉断后进入卸载阶段, 可以看出荷载一位移曲线的 斜率为负 ${ }^{[2]}$ 。

\section{参考文献}

[1]GB/T 50152-2012 混凝土结构试验方法标准[S].

[2]张宽.PC 钢棒预应力混凝土板正截面承载力试验研究 [D].哈 尔滨:哈尔滨工业大学,2011.

能实现双向 1080P 高清可视、全双工对讲。(2)通话转接。护士 站可将家属分机的探视请求转接至对应的床位分机。护士站 探视管理主机可监听监视探视过程, 可根据患者通话情况进 行插话或切断。(3)时间设定。系统可设定家属和患者探视通话 时长。数据同步系统可对接医院 HIS 系统, 病床分机可同步 显示病人基本信息。(4)录音录像。系统支持录音录像及远程查 看播放录制的文件，可将探视双方的音视频在一个页面中同 步播放显示。(5)远程探视。系统支持远程探视功能, 患者家属 可通过远程探视 App 与住院患者视频通话。(6门禁管理。病 区门口机具有刷看、密码开门功能; 支持与护士站主机可视对 讲及远程开门。

\section{4 结语}

智慧医院的设计理念归纳起来就是“以患者为中心 , 以医 学为基础, 以使用为目的, 以服务为宗旨”。医院的智能化技术 还有很多, 随着科学技术的发展, 智慧医院将趋于实现医疗现 代化和病房家庭化 ${ }^{[1]}$

\section{参考文献}

[1]李洪军.现代化医院建设基本功能探讨 $[\mathrm{J}]$.中国医用工程与装 备,2019,3(26):56. 